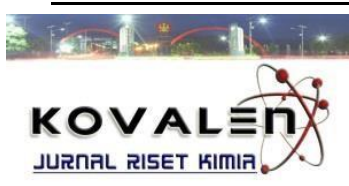

\title{
KARAKTERISASI SILIKA DARI ABU AMPAS TEBU
}

\section{[Characterization of Silica from Sugarcane Bagasse Ash]}

\section{Tifa Paramitha ${ }^{{ }^{\star}}$, Tri Reksa Saputra ${ }^{1}$, Amelia Nur Aliah ${ }^{1}$, Arijan Vevayose Tarigan ${ }^{1}$, Mukhtar Ghozali ${ }^{1}$}

\author{
1) Jurusan Teknik Kimia, Politeknik Negeri Bandung \\ Jl. Gegerkalong Hilir, Desa Ciwaruga, Kecamatan Parongpong, Kabupaten Bandung Barat, Indonesia
}

*) Coresponding Author: tifa.paramitha@polban.ac.id (hp: +6285232108308)

Diterima 13 November 2019, Disetujui 12 Desember 2019

\begin{abstract}
Silica has been successfully extracted from sugarcane bagasse ash by using alkali method. Extraction was carried out using sodium hydroxide solution to obtain sodium silicate solution and solid residue. Then, hydrochloric acid solution was added to sodium silicate solution until $\mathrm{pH}$ of solution was 7 and silica was formed. Furthermore, silica was heated in oven at $150{ }^{\circ} \mathrm{C}$ and calcined at 700 ${ }^{\circ} \mathrm{C}$. Variation of this study were extraction time (1,2 and 3 hours). The synthesized silica were characterized functional groups, acidity level, water adsorption ability and adsorption ability of $\mathrm{Cu}^{2+}$ ion. The results of FTIR analysis showed that all silica contain siloxane group. Silanol group did not appear because during calcination process occured the condensation reaction of silanol group. Other characterization results showed that silica with extraction time of 2 hours had highest acidity level, water adsorption ability and adsorption ability of $\mathrm{Cu}^{2+}$ ion, which were $6.201 \mathrm{mmol} / \mathrm{gram}, 86.41 \%$ and $92.55 \%$.
\end{abstract}

Keywords : bagasse ash, extraction, silica, siloxane

\begin{abstract}
ABSTRAK
Silika telah berhasil diekstraksi dari abu ampas tebu dengan metode alkali. Ekstraksi silika dilakukan dengan menggunakan larutan natrium hidroksida sehingga diperoleh larutan natrium silikat dan residu padatan. Selanjutnya, larutan asam klorida ditambahkan pada larutan sodium silikat hingga $\mathrm{pH}$ larutan adalah 7 dan terbentuk silika. Kemudian, silika dipanaskan di oven pada suhu $150{ }^{\circ} \mathrm{C}$ dan dikalsinasi pada suhu $700{ }^{\circ} \mathrm{C}$. Variasi penelitian ini adalah waktu proses ekstraksi (1, 2 dan 3 jam). Silika hasil sintesis dikarakterisasi gugus fungsional, nilai keasaman, kemampuan penjerapan air dan kemampuan adsorpsi ion $\mathrm{Cu}^{2+}$. Hasil analisis FTIR menunjukkan bahwa semua silika mengandung gugus siloksan. Gugus silanol tidak muncul karena selama proses kalsinasi mengalami reaksi kondensasi. Hasil karakterisasi lainnya menunjukkan bahwa silika dengan waktu proses ekstraksi 2 jam memiliki nilai keasaman, kemampuan penjerapan air dan kemampuan adsorpsi ion $\mathrm{Cu}^{2+}$ yang paling tinggi, yaitu $6,201 \mathrm{mmol} / \mathrm{gram}, 86,41 \%$ dan $92,55 \%$.
\end{abstract}

Kata kunci: abu ampas tebu, ekstraksi, silika, siloksan 


\section{LATAR BELAKANG}

Bagi masyarakat Indonesia, gula merupakan salah satu kebutuhan pokok. Bahan baku untuk produksi gula adalah tebu. Proses produksi gula menghasilkan limbah berupa ampas tebu. Dalam satu siklus proses produksi gula dihasilkan limbah ampas tebu sebesar $32 \%$. Setiap tahunnya, ampas tebu yang dihasilkan pada pabrik gula sejumlah 0,8 juta ton (lqbal et al., 2016). Ampas tebu dapat diutilisasi sebagai bahan bakar untuk pemanasan bolier karena kandungan $\mathrm{C}$ yang cukup tinggi. Limbah padat dari proses pembakaran tersebut adalah abu ampas tebu dengan kadar silika $\left(\mathrm{SiO}_{2}\right)$ yang relatif tinggi.

Berdasarkan Affandi et al. (2009), persentase silika pada abu ampas tebu yaitu sekitar $50 \%$. Dengan demikian, abu ampas tebu berpotensi untuk dimanfaatkan sebagai bahan baku sintesis partikel silika. Silika adalah padatan yang terbentuk melalui penggumpalan larutan natrium silikat yang telah ditambahkan larutan asam. Silika dapat diaplikasikan pada berbagai bidang, seperti pengisi beton, adsorben, penopang katalis, bidang kosmetik, bidang obat-obatan dan lain-lain.

Berdasarkan Handayani et al. (2015), silika dapat diekstraksi dari bahan alam, yaitu abu sekam padi. Prosedurnya adalah abu sekam padi direaksikan dengan larutan $\mathrm{NaOH}$ sehingga diperoleh larutan natrium silikat dan residu padatan. Selanjutnya, larutan natrium silikat yang bebas dari residu padatan ditambahkan larutan asam $(\mathrm{HCl})$ hingga terbentuk padatan silika. Padatan silika dikeringkan di dalam oven hingga diperoleh silika gel kering dan berwarna putih. Berdasarkan penelitian tersebut, yield silika gel kering sebesar $91,593 \%$.

Fatriansyah et al. (2018) juga telah berhasil mengekstraksi silika berasal dari abu sekam padi dengan memvariasikan jenis larutan asam yang digunakan pada proses pengasaman. Pada penelitian tersebut digunakan larutan $\mathrm{HCl}$ (asam kuat) dan larutan $\mathrm{CH}_{3} \mathrm{COOH}$ (asam lemah) serta diidentifikasi pengaruhnya terhadap persentase berat silika $\left(\mathrm{SiO}_{2}\right)$. Hasil penelitian menyatakan bahwa proses pengasaman dengan larutan $\mathrm{HCl}$ menghasilkan persentase berat silika yang lebih besar dibandingkan dengan proses pengasaman dengan larutan $\mathrm{CH}_{3} \mathrm{COOH}$. Fenomena ini disebabkan selama proses pengasaman dengan larutan $\mathrm{CH}_{3} \mathrm{COOH}$ dihasilkan garam $\mathrm{CH}_{3} \mathrm{COONa}$ yang bersifat basa sehingga menghambat proses pengendapan silika.

Berdasarkan beberapa literatur, silika hasil sintesis dapat diaplikasikan sebagai adsorben pada ion logam berat, seperti $\mathrm{Mn}^{2+}, \mathrm{Cu}^{2+}, \mathrm{Cd}^{2+}, \mathrm{Cr}^{6+}$ dan lain-lain. Ion logam berat adalah polutan yang banyak dihasilkan di berbagai air limbah industri, seperti pada fasilitas elektroplating, produksi cat dan industri tekstil. Ion logam berat tidak dapat terbiodegradasi sehingga dapat menyebabkan berbagai penyakit pada organisme hidup (Motsi et al., 2009).

Berdasarkan uraian di atas, peneliti 
melakukan ekstraksi silika dari abu ampas tebu dengan larutan $\mathrm{NaOH}$ dan dilanjutkan dengan proses pengasaman dengan larutan $\mathrm{HCl}$. Silika yang dihasilkan diidentifikasi gugus fungsional, nilai keasaman, persentase penjerapan air dan adsorpsi ion logam berat $\mathrm{Cu}^{2+}$.

\section{METODE PENELITIAN}

\section{Bahan dan Peralatan}

Bahan yang digunakan yaitu ampas tebu, natrium hidroksida $(\mathrm{NaOH})$, asam klorida $(\mathrm{HCl})$, hidrogen peroksida $\left(\mathrm{H}_{2} \mathrm{O}_{2}\right)$, asam sulfat $\left(\mathrm{H}_{2} \mathrm{SO}_{4}\right)$, larutan standar ion tembaga 10 ppm, dan aquadest.

Peralatan yang digunakan dalam ekstraksi silika dan karakterisasinya adalah tungku pembakaran, ayakan ukuran 300 mesh, hotplate, stirrer, furnace, oven, pompa vakum, desikator, neraca analitik, termometer, gelas ukur, labu ukur, gelas kimia, cawan porselen, buret, batang pengaduk dan erlenmeyer.

\section{Prosedur Penelitian}

\section{Pengabuan ampas tebu}

Ampas tebu kering dibakar menggunakan tungku pembakaran. Kemudian, abu ampas tebu diayak menggunakan ayakan ukuran 300 mesh sehingga dapat terpisahkan antara abu halus dengan abu yang masih kasar.

\section{Ekstraksi silika dari abu ampas tebu}

Proses ini dilakukan dengan menambahkan larutan $\mathrm{NaOH}(250 \mathrm{ml}$ aquadest dan 12,5 gram $\mathrm{NaOH}$ padat) ke dalam erlenmeyer yang berisi 10 gram abu ampas tebu. Kemudian, campuran diaduk dan dipanaskan pada suhu $80{ }^{\circ} \mathrm{C}$. Variasi waktu proses ekstraksi adalah 1,2 dan 3 jam. Hasil ekstraksi dipisahkan dengan cara filtrasi antara larutan natrium silikat $\left(\mathrm{Na}_{2} \mathrm{SiO}_{3}\right)$ dan residu padatan.

Proses selanjutnya adalah proses pengasaman. Larutan $\mathrm{HCl} 1 \mathrm{M}$ ditambahkan setetes demi setetes pada larutan natrium silikat sampai $\mathrm{pH}$ akhir larutan 7 dan terbentuk silika. Silika dipisahkan dari larutan garam terlarut dengan filtrasi vakum. Selanjutnya, silika dicuci dengan aquadest untuk menghilangkan pengotor dan diputihkan dengan larutan hidrogen peroksida $\left(\mathrm{H}_{2} \mathrm{O}_{2}\right)$. Silika yang telah bersih dikeringkan selama 24 jam pada suhu $150{ }^{\circ} \mathrm{C}$. Kemudian, silika kering digerus dengan mortar untuk memperkecil ukuran hingga diperoleh bubuk silika dan dilanjutkan proses kalsinasi selama 3 jam pada suhu $700^{\circ} \mathrm{C}$.

\section{Karakterisasi}

\section{Analisis dengan FTIR}

Fourier Transform Infra Red Spectrophotometer (FTIR) digunakan untuk mengidentifikasi gugus fungsional silika. Spektrum IR dicatat pada daerah serapan rentang panjang gelombang $4000 \mathrm{~cm}^{-1}$ $500 \mathrm{~cm}^{-1}$.

\section{Analisis Keasaman}

Analisis keasaman silika mengikuti Kristianingrum et al. (2011). Analisis keasaman dilakukan berdasarkan metode volumetri. $\quad 100 \mathrm{mg}$ silika kering dicampurkan dengan $15 \mathrm{ml}$ larutan $\mathrm{NaOH}$ 
0,1 M. Campuran didiamkan pada suhu ruang dalam waktu 24 jam. Selanjutnya, campuran disaring dan konsentrasi larutan $\mathrm{NaOH}$ akhir ditentukan dengan melakukan titrasi larutan $\mathrm{NaOH}$ akhir dengan larutan $\mathrm{H}_{2} \mathrm{SO}_{4} 0,1 \mathrm{M}$.

$$
\begin{aligned}
\text { keasaman } & =\frac{\text { mmol } \mathrm{NaOH} \text { awal }- \text { mmol NaOH sisa }}{\text { berat silika }} \\
\text { keasaman } & =\frac{\mathrm{V}_{\mathrm{NaOH}} \times \mathrm{M}_{\mathrm{NaOH}}-\mathrm{V}_{\mathrm{H}_{2} \mathrm{SO}_{4}} \times \mathrm{M}_{\mathrm{H}_{2} \mathrm{SO}_{4}}}{\text { berat silika }}
\end{aligned}
$$

\section{Analisis Penjerapan Air}

Analisis penjerapan air pada silika mengikuti Rungrodnimitchai et al. (2009). 0,5 gram silika kering dimasukkan dalam cawan porselen. Selanjutnya, silika diinkubasi dalam desikator. Kelembaban udara di dalam desikator dibuat jenuh dengan meletakkan gelas kimia yang berisi aquadest sejumlah $300 \mathrm{ml}$. Perubahan berat silika dicatat hingga hari ke-10.

$$
\begin{aligned}
& \% \text { penjerapan air }=\frac{\mathrm{m}_{2}-\mathrm{m}_{1}}{\mathrm{~m}_{1}} \times 100 \% \\
& \mathrm{~m}_{1}=\text { berat silika awal }(\mathrm{mg}) \\
& \mathrm{m}_{2}=\text { berat silika akhir }(\mathrm{mg})
\end{aligned}
$$

\section{Analisis Adsorpsi Ion Logam Tembaga $\left(\mathrm{Cu}^{2+}\right)$}

Analisis performansi silika dalam mengadsorpsi ion logam tembaga $\left(\mathrm{Cu}^{2+}\right)$ dilakukan secara batch dengan mencampurkan $50 \mathrm{mg}$ silika dan $50 \mathrm{ml}$ larutan ion logam $\mathrm{Cu}^{2+} 10 \mathrm{ppm}$. $\mathrm{pH}$ awal larutan ion logam $\mathrm{Cu}^{2+}$ adalah 2 . Campuran tersebut diaduk dengan bantuan stirrer selama 90 menit. Selanjutnya, campuran dipisahkan antara filtrat dan padatan silika. Konsentrasi ion logam $\mathrm{Cu}^{2+}$ dalam filtrat ditentukan dengan Atomic Absorption Spectroscopy (AAS).

$$
\begin{gathered}
\% \text { adsorpsi }=\frac{\mathrm{C}_{\mathrm{awal}}-\mathrm{C}_{\mathrm{akhir}}}{\mathrm{C}_{\mathrm{awal}}} \times 100 \% \\
\mathrm{C}_{\mathrm{awal}}=\text { konsentrasi awal ion } \mathrm{Cu}^{2+}(\mathrm{ppm}) \\
\mathrm{C}_{\mathrm{akhir}}=\text { konsentrasi akhir ion } \mathrm{Cu}^{2+}(\mathrm{ppm})
\end{gathered}
$$

\section{HASIL DAN PEMBAHASAN}

\section{Ekstrak Silika dari Abu Ampas Tebu}

Metode ekstraksi silika dari abu ampas tebu adalah metode alkali. Larutan alkali yang dicampurkan pada abu ampas tebu adalah larutan $\mathrm{NaOH} 5 \%$ (b/v). Selanjutnya, campuran dipanaskan pada suhu $80^{\circ} \mathrm{C}$. Variasi waktu proses ekstraksi adalah 1, 2 dan 3 jam. Hasil dari ekstraksi berupa larutan natrium silikat $\left(\mathrm{Na}_{2} \mathrm{SiO}_{3}\right)$ dan residu padatan. Larutan natrium silikat merupakan bahan dasar pembuatan silika. Reaksi dari silika dalam abu ampas tebu dengan larutan natrium hidroksida dijelaskan sebagai berikut.

$$
\mathrm{SiO}_{2(\mathrm{~s})}+2 \mathrm{NaOH}_{(\mathrm{aq})} \rightarrow \mathrm{Na}_{2} \mathrm{SiO}_{3(\mathrm{aq})}+\mathrm{H}_{2} \mathrm{O}_{(\mathrm{l})}
$$

Fenomena reaksi di atas telah dijelaskan oleh Aeni et al. (2017). Mulanya, larutan $\mathrm{NaOH}$ mengalami disosiasi sempurna sehingga terbentuk ion $\mathrm{Na}^{+}$dan $\mathrm{OH}^{-}$di dalam air. Selanjutnya, terjadi reaksi adisi antara ion $\mathrm{OH}^{-}$dengan atom $\mathrm{Si}=\mathrm{O}$ pada $\mathrm{SiO}_{2}$ sehingga diperoleh $\mathrm{SiO}_{2} \mathrm{OH}$. Kemudian, ion $\mathrm{OH}^{-}$kedua menyerang $\mathrm{H}^{+}$ pada gugus $\mathrm{OH}$ dalam $\mathrm{SiO}_{2} \mathrm{OH}$ sehingga membentuk molekul air dan $\mathrm{SiO}_{3}{ }^{2-} \cdot \mathrm{SiO}_{3}{ }^{2-}$ bereaksi dengan dua ion $\mathrm{Na}^{+}$membentuk $\mathrm{Na}_{2} \mathrm{SiO}_{3}$. 
Proses selanjutnya adalah mengatur $\mathrm{pH}$ larutan natrium silikat hingga mencapai $\mathrm{pH}$ 7. Penambahan asam bertujuan untuk memisahkan silika (sukar larut terhadap larutan asam) dari ion $\mathrm{Na}^{+}$. Reaksi pada proses pengasaman dijabarkan sebagai berikut (Aeni et al., 2017).

$$
\begin{gathered}
\mathrm{Na}_{2} \mathrm{SiO}_{3(\mathrm{aq})}+2 \mathrm{HCl}_{(\mathrm{aq})} \rightarrow \mathrm{H}_{2} \mathrm{SiO}_{3(\mathrm{aq})}+2 \mathrm{NaCl}_{(\mathrm{aq})} \\
\mathrm{H}_{2} \mathrm{SiO}_{3(\mathrm{aq})} \rightarrow \mathrm{SiO}_{2(\mathrm{~s})}+2 \mathrm{H}_{2} \mathrm{O}_{(\mathrm{l})}
\end{gathered}
$$

Silika yang terbentuk dipisahkan dengan filtratnya. Kemudian, silika dicuci dengan aquadest dan diputihkan dengan larutan $\mathrm{H}_{2} \mathrm{O}_{2}$. Silika yang telah bersih dikeringkan dan dikalsinasi.

\section{Karakteristik Silika Hasil Sintesis}

\section{Karakterisasi silika dengan FTIR}

Gambar 1 merupakan spektrum hasil analisis dengan FTIR pada silika dengan variasi waktu proses ekstraksi. FTIR digunakan untuk mengetahui gugus fungsional dari silika. Berdasarkan Gambar 1 dapat diindentifikasi adanya pita serapan pada panjang gelombang di daerah sekitar $1.180-1.080 \mathrm{~cm}^{-1}, 820-790 \mathrm{~cm}^{-1}$ dan sekitar $600 \mathrm{~cm}^{-1}$.

Tabel 1 Identifikasi spektrum FTIR silika hasil

\begin{tabular}{|c|c|c|c|}
\hline \multicolumn{3}{|c|}{ Panjang gelombang $\left(\mathrm{cm}^{-1}\right)$} & \multirow{2}{*}{ Keterangan } \\
\hline 1 jam & 2 jam & 3 jam & \\
\hline 1064,71 & 1070,26 & 1063,61 & $\begin{array}{c}\text { Vibrasi ulur } \\
\text { asimetri Si-O } \\
\text { dari Si-O-Si }\end{array}$ \\
\hline 803,04 & 793,87 & 797,14 & $\begin{array}{l}\text { Vibrasi ulur } \\
\text { simetri Si-O } \\
\text { dari Si-O-Si }\end{array}$ \\
\hline 623,12 & 611,01 & 619,19 & $\begin{array}{c}\text { Vibrasi tekuk } \\
\text { Si-O dari Si- } \\
\mathrm{O}^{-S i}\end{array}$ \\
\hline
\end{tabular}
sintesis
Identifikasi lebih lengkap pada Tabel 1 menunjukkan bahwa semua silika mengandung gugus siloksan atau Si-O-Si. Namun, gugus silanol atau $\mathrm{Si}-\mathrm{OH}$ tidak teridentifikasi dalam analisis dengan FTIR ini. Hal ini ditunjukkan dengan tidak muncul pita serapan gugus silanol pada panjang gelombang sekitar $900 \mathrm{~cm}^{-1}$ dan 3.700$3.200 \mathrm{~cm}^{-1}$.
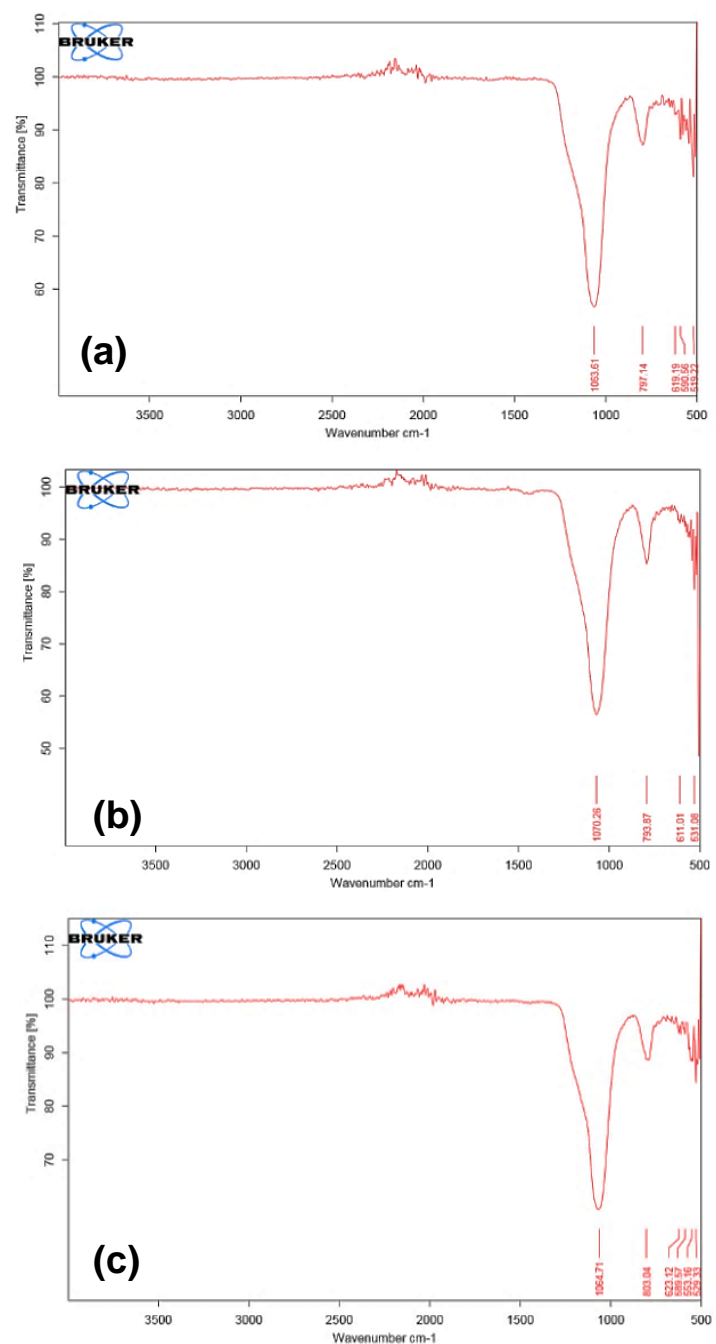

Gambar 1 Spektrum FTIR pada silika dengan waktu proses ekstraksi (a) 1 jam (b) 2 jam dan (c) 3 jam

Fenomena yang terjadi dijelaskan sebagai berikut. Produk silika yang dihasilkan pada penelitian ini adalah silika yang telah dikalsinasi pada suhu $700{ }^{\circ} \mathrm{C}$. Proses 
kalsinasi bertujuan untuk pelepasan kandungan air dan senyawa organik yang tersisa. Berdasarkan Nuryono dan Narsito (2005), ada dua reaksi pelepasan molekul air di silika selama proses kalsinasi, yaitu reaksi pemutusan ikatan hidrogen yang terbentuk antara gugus silanol dengan molekul air dan reaksi kondensasi gugus silanol pada silika menjadi gugus siloksan dan air. Dengan demikian, keseluruhan gugus silanol telah terkonversi menjadi gugus siloksan selama proses kalsinasi. Reaksi kondensasi gugus silanol menjadi gugus siloksan dan air adalah sebagai berikut (Nuryono dan Narsito, 2005).

$$
2 \equiv \mathrm{Si}-\mathrm{OH} \rightarrow \equiv \mathrm{Si}-\mathrm{O}-\mathrm{Si} \equiv+\mathrm{H}_{2} \mathrm{O}
$$

\section{Sifat keasaman silika}

Analisis keasaman silika dilakukan dengan merendam silika dalam larutan $\mathrm{NaOH}$. Selama perendaman, ion $\mathrm{OH}^{-}$pada larutan $\mathrm{NaOH}$ bereaksi dengan gugus silanol pada silika sehingga dihasilkan air. Namun, hasil analisis dengan FTIR yang dijelaskan pada sub bab sebelumnya menyatakan bahwa tidak munculnya pita serapan pada panjang gelombang yang sesuai dengan gugus silanol.

Hal ini diduga kandungan gugus silanol terbentuk selama proses perendaman. Gugus siloksan yang terkandung dalam silika bereaksi dengan molekul air membentuk gugus silanol. Berdasarkan Sulastri dan Kristianingrum (2010), ada jenis gugus siloksan yang mampu bereaksi secara kemisorpsi dengan air yaitu gugus siloksan yang membentuk lingkar dengan empat anggota. Reaksi gugus siloksan menjadi silanol dituliskan sebagai berikut.

$$
\equiv \mathrm{Si}-\mathrm{O}-\mathrm{Si} \equiv+\mathrm{H}_{2} \mathrm{O} \rightarrow 2 \equiv \mathrm{Si}-\mathrm{OH}
$$

Setelah gugus silanol terbentuk terjadilah reaksi antara gugus silanol dengan ion $\mathrm{OH}^{-}$pada larutan $\mathrm{NaOH}$. Reaksinya disajikan sebagai berikut (Kristianingrum et al., 2011).

$$
\equiv \mathrm{Si}-\mathrm{OH}+\mathrm{OH}^{-} \rightarrow \equiv \mathrm{Si}-\mathrm{O}^{-}+\mathrm{H}_{2} \mathrm{O}
$$

Nilai keasaman silika dihitung berdasarkan selisih mmol $\mathrm{NaOH}$ diawal dan diakhir perendaman per gram silika. Tabel 2 merupakan nilai keasaman silika.

Tabel 2. Nilai keasaman silika hasil sintesis

\begin{tabular}{cc}
\hline $\begin{array}{c}\text { Waktu proses } \\
\text { ekstraksi (jam) }\end{array}$ & $\begin{array}{c}\text { Nilai keasaman } \\
\text { (mmol/gram) }\end{array}$ \\
\hline 1 & 5,889 \\
2 & 6,201 \\
3 & 6,045 \\
\hline
\end{tabular}

Berdasarkan Tabel 2 diketahui bahwa nilai keasaman tertinggi dimiliki oleh silika dengan waktu proses ekstraksi 2 jam. Nilai keasaman mengindikasikan jumlah gugus silanol yang terkandung dalam silika. Dengan demikian, silika dengan waktu proses ekstraksi 2 jam memiliki gugus silanol tertinggi selama perendaman.

\section{Kemampuan silika terhadap penjerapan air}

Salah satu aplikasi silika adalah sebagai adsorben. Gambar 2 menyajikan kemampuan silika dalam menjerap air di desikator selama 10 hari. Kelembaban udara di dalam desikator dibuat jenuh 
dengan meletakkan gelas kimia yang berisi aquadest sejumlah $300 \mathrm{ml}$ di desikator.

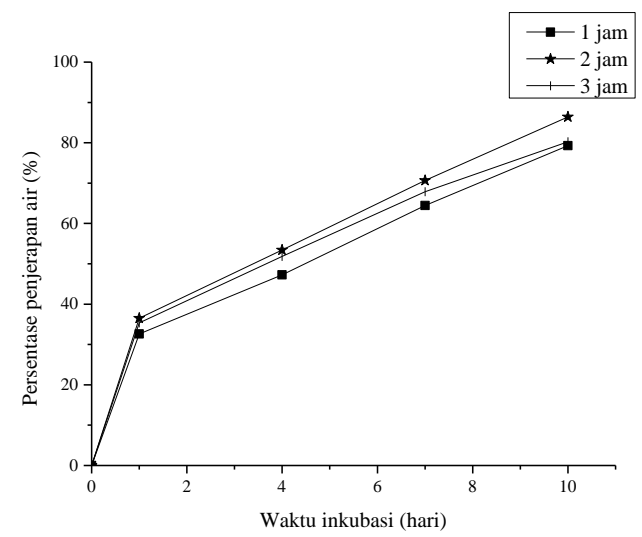

Gambar 2. Kemampuan silika dalam penjerapan air

Dari Gambar 2 terlihat bahwa silika mampu menjerap air dengan sangat cepat pada awal inkubasi. Fenomena ini disebabkan masih banyak gugus aktif yang tersedia di awal inkubasi sehingga air dapat berinteraksi lebih mudah dengan silika. Selain itu, penjerapan yang sangat cepat di awal inkubasi disebabkan oleh driving force (kekuatan pendorong) yang tinggi dimana dapat dilihat dari perbedaan konsentrasi air yang besar antara kelembaban udara dalam desikator dengan silika. Kemudian, sebagian gugus aktif telah menjerap air sehingga laju penjerapan menjadi lebih lambat. Pada hari ke-1 inkubasi, silika dengan waktu proses ekstraksi 1, 2 dan 3 jam mampu menjerap air sebesar 32,60\%, 36,50\% dan $35,36 \%(b / b)$.

Berdasarkan Gambar 2 juga dapat diketahui bahwa semakin lama waktu inkubasi silika dalam desikator maka persentase penjerapan air semakin besar. Hal ini disebabkan bahwa semakin lama waktu inkubasi silika dalam desikator maka semakin lama pula waktu kontak antara silika dengan air. Pada hari inkubasi ke-10, persentase penjerapan air berturut-turut dari silika dengan waktu proses ekstraksi 1, 2 dan 3 jam adalah 79,29\%, 86,41\% dan $80,27 \%$. Kemampuan penjerapan silika terhadap air tidak dipengaruhi oleh banyaknya gugus siloksan dan gugus silanol dari silika, tetapi disebabkan oleh distribusi gugus - $\mathrm{OH}$ per unit area silika (Nuryono dan Narsito, 2005). Diantara tiga sampel silika hasil analisis, silika dengan waktu proses ekstraksi 2 jam mampu menjerap air paling banyak dan menandakan bahwa gugus $-\mathrm{OH}$ paling banyak.

\section{Karakterisasi Kemampuan Silika dalam Adsorpsi Ion Logam Tembaga $\left(\mathrm{Cu}^{2+}\right)$}

Pada penelitian ini, silika dianalisis performansinya dalam adsorpsi ion logam berat. Fenomena interaksi antara silika dan ion logam berat dijelaskan oleh Azmiyawati et al. (2019). Mulanya, gugus aktif $-\mathrm{OH}$ pada silika akan melepaskan $\mathrm{H}^{+}$dan membentuk $\mathrm{O}^{-}$. Selanjutnya, $\mathrm{O}^{-}$mengikat logam berat (hard metals) karena $\mathrm{O}^{-}$adalah basa keras (hard base)

Analisis performansi dilakukan dengan cara mengontakkan $50 \mathrm{mg}$ silika dengan $50 \mathrm{ml}$ larutan yang mengandung ion $\mathrm{Cu}^{2+} 10$ ppm selama 90 menit. $\mathrm{pH}$ awal larutan ion $\mathrm{Cu}^{2+}$ diatur sebesar 2. Hal ini dilakukan untuk menghindari terjadinya pengendapan ion $\mathrm{Cu}^{2+}$ selama proses adsorpsi. Berdasarkan Said (2010), ion 
$\mathrm{Cu}^{2+}$ mulai mengendap pada $\mathrm{pH}$ 8,5-9,5. Kemudian, larutan akhir proses adsorpsi diidentifikasi kandungan ion $\mathrm{Cu}^{2+}$ dengan AAS. Persentase adsorpsi ion $\mathrm{Cu}^{2+}$ dapat dilihat pada Tabel 3.

Tabel 3. Persentase adsorpsi ion $\mathrm{Cu}^{2+}$

\begin{tabular}{cc}
\hline $\begin{array}{c}\text { Waktu proses } \\
\text { ekstraksi (jam) }\end{array}$ & $\begin{array}{c}\text { Persentase adsorpsi } \\
(\%)\end{array}$ \\
\hline 1 & $73,20 \%$ \\
2 & $92,55 \%$ \\
3 & $100 \%$ \\
\hline
\end{tabular}

Berdasarkan Tabel 3 menunjukkan bahwa silika dengan waktu proses ekstraksi 1 jam memiliki kemampuan adsorpsi ion $\mathrm{Cu}^{2+}$ paling rendah. Persentase adsorpsi ion $\mathrm{Cu}^{2+}$ pada silika dengan waktu proses ekstraksi 1 jam adalah $73,20 \%$. Disisi lain, silika dengan waktu proses ekstraksi 2 jam dan 3 jam memiliki kemampuan adsorpsi ion $\mathrm{Cu}^{2+}$ baik. Lebih dari $90 \%$ ion $\mathrm{Cu}^{2+}$ dapat teradsorpsi oleh silika dengan waktu proses ekstraksi 2 jam, sedangkan silika dengan waktu proses ekstraksi 3 jam mampu mengadsorpsi keseluruhan ion $\mathrm{Cu}^{2+}$ dalam larutan. Dengan demikian, dapat disimpulkan bahwa silika dengan waktu proses ekstraksi 2 dan 3 jam memiliki kemampuan adsorpsi yang cukup baik terhadap ion $\mathrm{Cu}^{2+}$.

\section{KESIMPULAN}

Ekstraksi silika dari abu ampas tebu telah berhasil dilakukan dengan metode alkali dan proses pengasaman dengan larutan asam klorida $(\mathrm{HCl})$. Hal ini ditunjukkan dari hasil analisis FTIR dimana silika mengandung gugus siloksan. Berdasarkan hasil karakterisasi yang lain, silika terbaik adalah silika yang diekstraksi dengan waktu proses ekstraksi 2 jam. Nilai keasaman, persentase penjerapan air dan persentase adsorpsi ion $\mathrm{Cu}^{2+}$ adalah 6,201 $\mathrm{mmol} / \mathrm{gram}, 86,41 \%$ dan $92,55 \%$.

\section{UCAPAN TERIMAKASIH}

Penulis mengucapkan terima kasih kepada UPPM Politeknik Negeri Bandung atas dukungan dana untuk penelitian ini melalui skema penelitian mandiri.

\section{DAFTAR PUSTAKA}

Aeni, D.N., Hadisantoso, E.P., dan Suhendar, D. 2017. Adsorpsi ion logam $\mathrm{Mn}^{2+}$ dan $\mathrm{Cu}^{2+}$ oleh silika gel dari abu ampas tebu. al-Kimiya. $4(2): 70-80$.

Affandi, S., Setyawan, H., Winardi, S., Purwanto, A., dan Balgis, R. 2009. A facile method for production of highpurity silica xerogels from bagasse ash. Adv. Powder. Tech. 20:468-472.

Azmiyawati, C., Niami, S.S., dan Darmawan, A. 2019. Synthesis of silica gel from glass waste for adsorption of $\mathrm{Mg}^{2+}, \mathrm{Cu}^{2+}$, and $\mathrm{Ag}^{+}$ metal ions. 13th Joint Conference on Chemistry. 509: 1-5.

Fatriansyah, J.F., Situmorang, F.W., dan Dhaneswara, D. 2018. Ekstraksi silika dari sekam padi: metode refluks dengan $\mathrm{NaOH}$ dan pengendapan menggunakan asam kuat $(\mathrm{HCl})$ dan asam lemah $\left(\mathrm{CH}_{3} \mathrm{COOH}\right)$. Seminar Nasional Fisika Universitas Riau ke-3, hal. 123-127.

Handayani, P.A., Nurjanah, E., dan Rengga, W.D.P. 2015. Pemanfaatan limbah sekam padi menjadi silika gel. JBAT. 4(2):55-59. 
lqbal, M., Elwina, Marita, Y. 2016. Pemanfaatan limbah ampas tebu dalam pembuatan silica gel. Jurnal Reaksi. 14(1):48-53.

Kristianingrum, S., Siswani, E.D., dan Fillaeli, A. 2011. Pengaruh jenis asam pada sintesis silika gel dari abu bagasse dan uji sifat adsorptifnya terhadap ion logam tembaga (II). Seminar Nasional Kimia, Yogyakarta. hal. 281-292.

Motsi, T., Rawson, N.A., Simmons, M.J.H. 2009. Adsorption of heavy metals from acid mine drainage by natural zeolite. Int. J. Miner. Process. 92:4248.

Nuryono dan Narsito. 2005. Effect of acid concentration on characters of silica gel synthesized from sodium silicate. Ind. J. Chem. 5(1):23-30.

Rungrodnimitchai, S., Phokhanusai, W., dan Sungkhaho, N. 2009. Preparation of silica gel from rice husk ash using microwave heating. Journal of Metals, Materials and Minerals. 19(2):45-50.

Said, N.I. 2010. Metoda penghilangan logam berat (As, Cd, Cr, $\mathrm{Ag}, \mathrm{Cu}, \mathrm{Pb}$, $\mathrm{Ni}$ dan $\mathrm{Zn}$ ) di dalam air limbah industri. JAI. 6(2):136-148.

Sulastri, S., dan Kristianingrum, S. 2010. Berbagai macam senyawa silika: sintesis, karakterisasi dan pemanfaatan. Prosiding Seminar Nasional Penelitian, Pendidikan dan Penerapan MIPA, Yogyakarta. hal. $\mathrm{K}-211-\mathrm{K}-216$. 